\title{
Detection of a Species-specific Antigen of Gardnerella vaginalis by Western Blot Analysis
}

\author{
By Y. L. BOUSTOULLER, * A. P. JOHNSON AND D. TAYLOR-ROBINSON \\ Division of Sexually Transmitted Diseases, MRC Clinical Research Centre, Watford Road, \\ Harrow, Middlesex HAl $3 U J, U K$
}

(Received 27 February 1986)

\begin{abstract}
Western blot analysis was used to identify antigenic components of Gardnerella vaginalis. Polypeptides bound to nitrocellulose membranes were probed with murine antisera raised to two strains of $G$. vaginalis, and antibody-antigen complexes were detected with ${ }^{125}$ I-labelled antimouse immunoglobulin followed by autoradiography. Although there was inter-strain variation in immunogenic polypeptide profiles, all 23 strains of $G$. vaginalis examined contained a common antigen of molecular mass $41 \mathrm{kDa}$. This antigen was not found in any of six other bacterial genera.
\end{abstract}

\section{INTRODUCTION}

In 1955 Gardner and Dukes described a micro-organism which they believed was the aetiological agent of non-specific vaginitis (NSV). Subsequently, however, controversy has surrounded both its role in disease and its taxonomic status. When first described, it was assigned to the genus Haemophilus. Further investigation showed that the micro-organism could be grown without $X$ and V factors, and Reyn et al. (1966) concluded that its electron microscopic appearance resembled that of a Gram-positive bacterium. On these grounds, it was reclassified as Corynebacterium vaginale, but as numerous investigators regarded the bacterium as being neither classical Gram-positive nor negative, it was assigned eventually to a novel genus and species, designated Gardnerella vaginalis (Greenwood \& Pickett, 1980).

The morphological, cultural, biochemical and serological characteristics of $G$. vaginalis have been studied in some detail (Taylor-Robinson, 1984). Its antigenic analysis, however, has been almost totally ignored, apart from the study by Smaron \& Vice (1974). They used an immunodiffusion technique and showed that all isolates of $G$. vaginalis examined had a common antigenic determinant. In this report we present the results of an investigation into the antigenic composition of $G$. vaginalis using the techniques of SDS-PAGE and Western blotting.

\section{METHODS}

Bacteria. Twenty-three strains of G. vaginalis, identified according to the criteria of Taylor \& Phillips (1983) were studied. Strains $3: 1,16: 1,26: 3,33: 4,39: 2,40: 1,42: 5,47: 3,49: 6,54: 1,67: 1,76: 1,76: 3$ and $81: 1$ were obtained from E. Taylor, St Thomas' Hospital Medical School, London, UK, strains 661, 662, 663, 673, 6376, 8821 and 10915 from C. Ison, St Mary's Hospital Medical School, London, and strains 762 and 763 from the Praed Street Clinic, London. The bacteria were grown routinely at $37^{\circ} \mathrm{C}$ for $48 \mathrm{~h}$ on Columbia agar containing $10 \%(\mathrm{v} / \mathrm{v})$ defibrinated sheep blood (Difco) in an atmosphere of $5 \%(\mathrm{v} / \mathrm{v}) \mathrm{CO}_{2}$ in air. Then the organisms were removed from the agar with a bacteriological loop, suspended in sterile distilled water and washed by centrifugation. The pellet was resuspended in distilled water and the suspension stored at $-20^{\circ} \mathrm{C}$. In several experiments, the bacteria were grown in peptone/starch/dextrose (PSD) broth (Dunkelberg et al., 1970) containing 10\% (v/v) heat-inactivated $\left(56^{\circ} \mathrm{C}\right.$ for $\left.30 \mathrm{~min}\right)$ horse serum. The organisms were washed twice by centrifugation, resuspended in a small volume of distilled water and stored at $-20^{\circ} \mathrm{C}$. Bacteria ascribed to five other genera were also studied. These were: unclassified cornyneforms 25:6 and 56:3 (from E. Taylor); Neisseria gonorrhoeae 203H (authors' isolate); Haemophilus influenzae strains 2104 (authors' isolate), Eagan (from T. Inzana, Washington State University, USA) 
and H126 (from R. Wall, CRC, Harrow); Campylobacter fetus 3329 and C. jejuni 42739 (from A. O'Sullivan, CRC, Harrow); and Bacteroides ureolyticus W2N12 (from E. Fontaine, CRC, Harrow). Apart from Neisseria gonorrhoeae, which was grown on chocolate agar, and Bacteroides ureolyticus, which was grown under anaerobic conditions, all the other micro-organisms were grown on Columbia agar, which was incubated and the organisms harvested as described previously.

Preparation of cell extracts. Before use, $100 \mu \mathrm{l}$ samples of each bacterial suspension were boiled for $3 \mathrm{~min}$ with $10 \mu 125 \%$ (w/v) SDS and the protein concentrations of the mixtures were assayed by the Lowry method. Then the bacterial suspension and sample buffer (Laemmli, 1970) were added in equal volumes (maximum total volume of $100 \mu \mathrm{l})$ to give a protein concentration of $60 \mu \mathrm{g}$ per sample. The preparations were boiled for 3-5 min, cooled, and particulate matter removed by centrifugation before applying to the gels.

$S D S-P A G E$. Whole-cell extracts were analysed on $10 \%(\mathrm{w} / \mathrm{v})$ acrylamide slab gels, according to the method of Laemmli (1970). Protein standards ranging from 14.4 to $195 \mathrm{kDa}$ (Bio-Rad) were run on each gel for molecular mass determinations and consistency comparisons. Gels were placed in a Protean I dual electrophoresis system (Bio-Rad) at a constant current of $30 \mathrm{~mA}$ per gel until the tracking dye (bromophenol blue) was $2 \mathrm{~cm}$ from the end of the gel. The gels were blotted as described below, or stained overnight with $0 \cdot 1 \%(\mathrm{w} / \mathrm{v})$ Coomassie Brilliant Blue R-250 (Bio-Rad) in water/methanol/acetic acid $(5: 5: 2$, by vol.) and destained in water/methanol/acetic acid ( $5: 3: 2$, by vol.).

Western blotting. The separated cellular components on the gels were transferred electrophoretically in a TransBlot cell (Bio-Rad) onto a $0 \cdot 2 \mu \mathrm{m}$ nitrocellulose membrane (Schleicher \& Schüll) as described by Towbin et al. (1979). After transfer, the outside lanes of the nitrocellulose filter, corresponding to the lanes of the gel that contained molecular mass markers, were removed, stained with $0.1 \%(\mathrm{w} / \mathrm{v})$ naphthol blue black (Sigma) for $2 \mathrm{~min}$ and destained in the solution described above. The remaining nitrocellulose membrane was washed in a buffer solution of $1 \%(\mathrm{w} / \mathrm{v}) \mathrm{BSA}, 0.001 \%(\mathrm{v} / \mathrm{v})$ Tween 20 in PBS ( $\mathrm{NaCl}, 8 \mathrm{~g} \mathrm{l}^{-1} ; \mathrm{KCl}, 0.2 \mathrm{~g} \mathrm{l}^{-1} ; \mathrm{Na}_{2} \mathrm{HPO}_{4}, 1.5 \mathrm{~g} \mathrm{l}^{-1}$; $\mathrm{KH}_{2} \mathrm{PO}_{4}, 0.2 \mathrm{~g}^{-1} ; \mathrm{pH} \mathrm{7.4)}$ for $1 \mathrm{~h}$ to block any remaining free sites on the membrame. The membrane was then immersed for $2 \mathrm{~h}$ in $G$. vaginalis antiserum diluted 1:500 in the BSA buffer solution described above. After washing for $30 \mathrm{~min}$ with three changes of buffer, the membrane was probed for $1 \mathrm{~h}$ with ${ }^{125}$ I-labelled rabbit antimouse immunoglobulins (Dako, Copenhagen), radiolabelled by the chloramine-T method (Greenwood et al., 1963); specific radioactivity was $5 \mu \mathrm{Ci}(\mu \mathrm{g} \text { protein })^{-1}\left[185 \mathrm{kBq}(\mu \mathrm{g} \text { protein })^{-1}\right]$ and the antibodies were used at $2 \times$ $10^{7}$ c.p.m. per blot. The membrane was then washed for $45 \mathrm{~min}$ in three changes of PBS, air-dried and exposed to Kodak X-Omat film with an intensifying screen at $-70^{\circ} \mathrm{C}$ for $1 \mathrm{~d}$ before developing.

G. vaginalis antisera. Antisera to strains $47: 3$ and 673 were prepared in groups of 10 specific pathogen-free TO mice. Each mouse was inoculated intravenously with $0.2 \mathrm{ml}$ of a freshly prepared suspension of $G$. vaginalis in PBS containing $10^{8}$ c.f.u. $\mathrm{ml}^{-1}$, the organisms having been grown for $48 \mathrm{~h}$ at $37^{\circ} \mathrm{C}$ as described previously. The inoculations were repeated $7 \mathrm{~d}$ later with another freshly prepared suspension, $3 \mathrm{~d}$ after which the mice were exsanguinated. The sera for each bacterial strain were pooled, separated by centrifugation and stored as small samples at $-70^{\circ} \mathrm{C}$.

Serum antibodies to $G$. vaginalis were measured by a micro-immunofluorescence technique (Wang et al., 1977), modified so that the organisms, suspended in PBS at a concentration of $1 \times 10^{8} \mathrm{c}$. f.u. $\mathrm{ml}^{-1}$, were not formalinized. The antibody titre was recorded as the reciprocal of the highest dilution of serum at which the bacteria fluoresced.

\section{RESULTS}

\section{Western blotting}

Twenty-three strains of $G$. vaginalis were examined in duplicate by Western blotting. Using ${ }^{125}$ I-labelled anti-mouse immunoglobulins as the probe, immune mouse serum to strain $47: 3$, which had an immunofluorescent antibody titre of 512 , recognized a wide variety of $G$. vaginalis proteins; the results of testing five representative strains are shown in Fig. 1. However, despite the variety of bands, all the strains of $G$. vaginalis had an immunodominant molecule which migrated to a distance corresponding to a molecular mass of $41 \mathrm{kDa}$ (SD $0.76 \mathrm{kDa}$ ) (arrowed in Fig. 1). Furthermore, this antigenic molecule could be seen with extracts not only from organisms grown on agar medium, but also from those grown in broth. Antibodies to the various antigenic components, including the $41 \mathrm{kDa}$ determinant, were not present in mouse serum as no immunogenic components could be found when blotting was done with serum from unimmunised mice.

Bacteria of other genera (see Methods), were examined to assess the specificity of the reaction with $G$. vaginalis. These bacteria were subjected to the same electrophoretic procedure and blotted with strain 47:3 G. vaginalis antiserum. Although some evidence of cross-reactivity was 


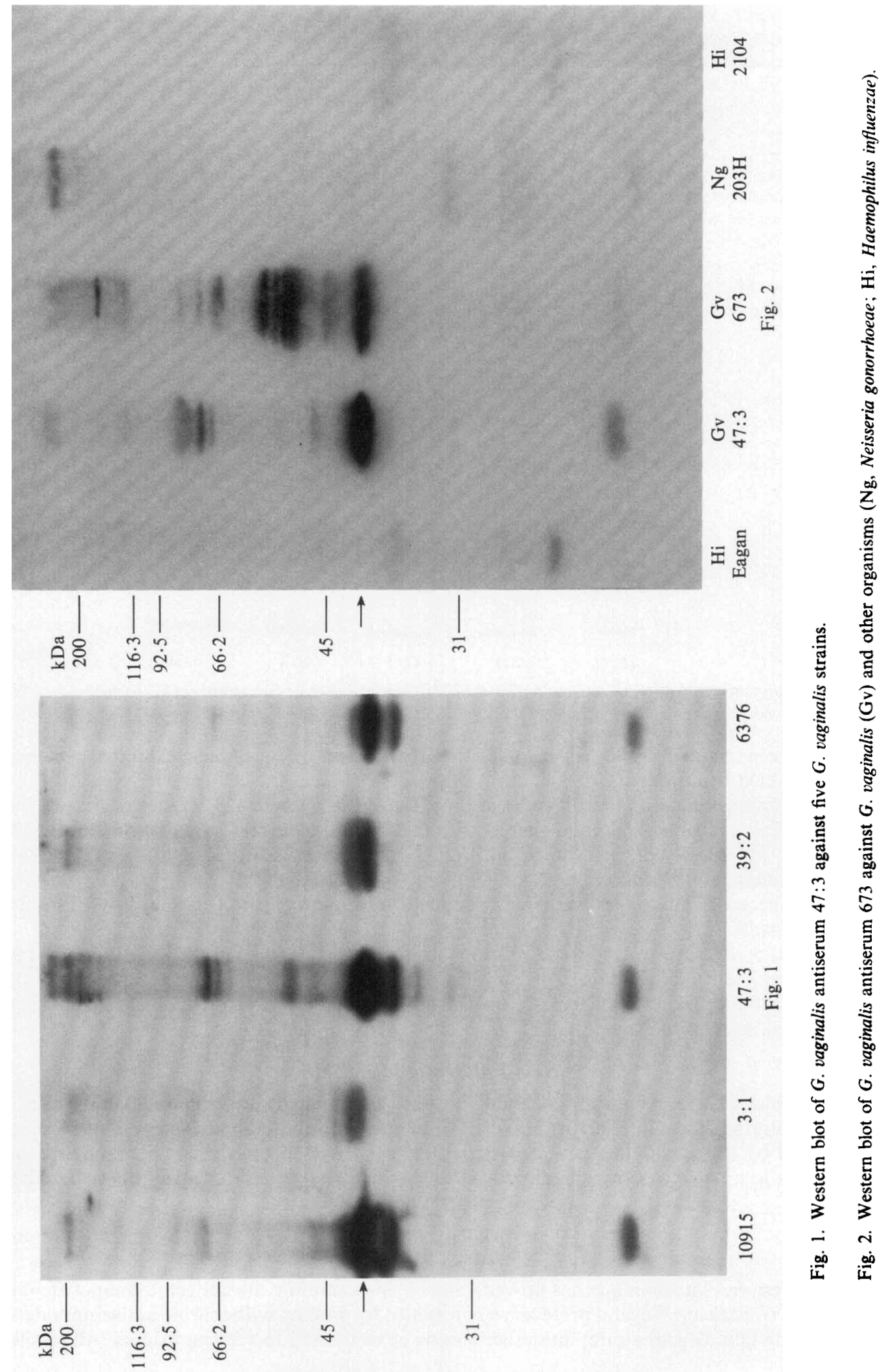




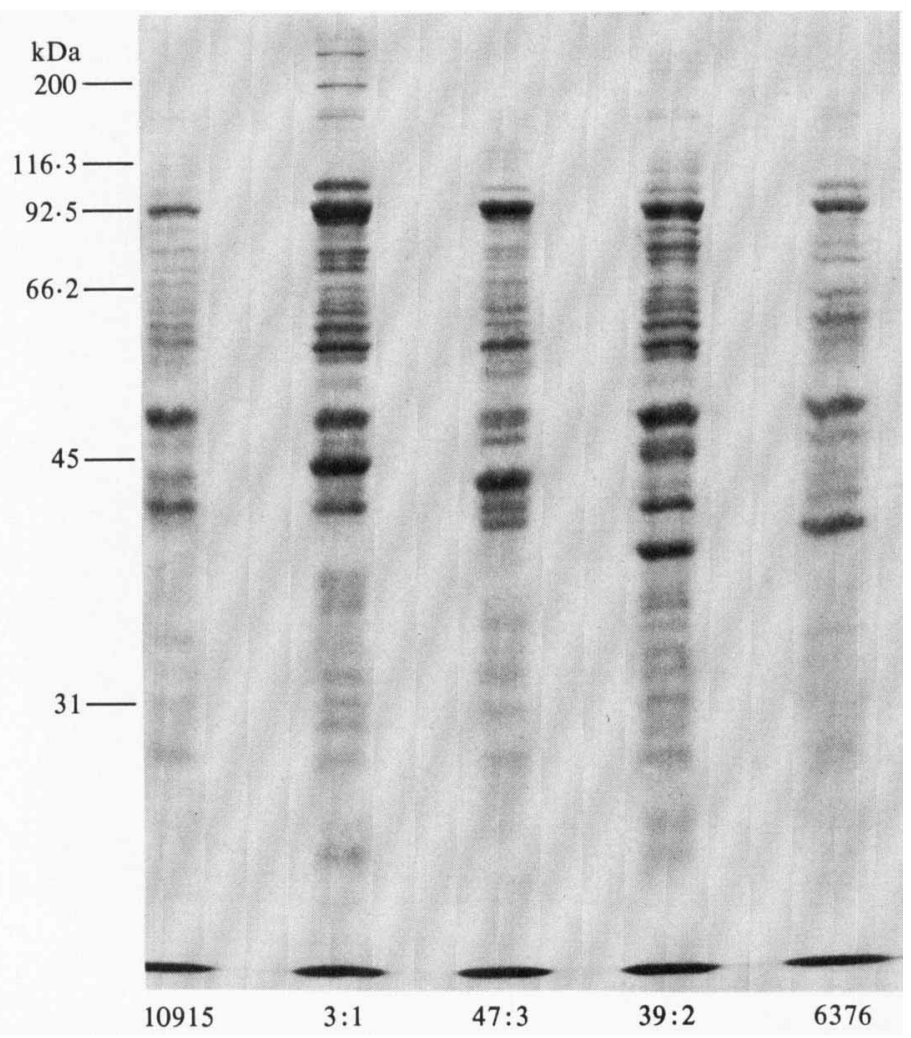

Fig. 3. SDS-PAGE protein profiles of whole-cell homogenates of five strains of G. vaginalis.

seen between strain $47: 3$ of $G$. vaginalis and the other bacteria, none of them exhibited evidence of the $41 \mathrm{kDa}$ determinant.

Mouse antiserum raised to a different strain of $G$. vaginalis, strain 673, was tested against the various strains of $G$. vaginalis and against the other bacteria. Several immunogenic molecules could be identified but, as shown in Fig. 2, G. vaginalis strains again exhibited an immunodominant molecule on the autoradiogram at $41 \mathrm{kDa}$ (arrowed) which was not seen with the other bacteria. This molecule therefore appears to be a specific antigen shared by all strains of $G$. vaginalis.

Extracts of several G. vaginalis strains were incubated at $37^{\circ} \mathrm{C}$ for $1 \mathrm{~h}$ with $50 \mu \mathrm{g}$ Proteinase $\mathrm{K}$ (Boehringer) before application to the polyacrylamide gels. No immunogenic components could be seen when they were blotted with $G$. vaginalis antiserum, whereas extracts which had not been pre-treated, and on the same gel, exhibited characteristic profiles.

\section{SDS-PAGE protein profiles}

The value of Western blotting was highlighted by examining the protein profiles of the five $G$. vaginalis strains shown in Fig. 1 by SDS-PAGE before blotting. As shown in Fig. 3, the strains examined by this technique exhibited some heterogeneity but there was no common band migrating to a distance corresponding to $41 \mathrm{kDa}$ which stained more heavily than any other band.

\section{DISCUSSION}

The Western blot technique has proved valuable in examining the antigenic composition of strains of $G$. vaginalis. Several proteins were revealed by probing with murine antiserum raised against the homologous strain, and other strains cross-reacted to varying extents. All strains 
examined, however, shared a common antigen of $41 \mathrm{kDa}$. This cross-reactive molecule was present in $G$. vaginalis strains irrespective of their mode of growth and was not seen in any of the five other bacterial genera examined. Smaron \& Vice (1974), using Ouchterlony analysis, showed that $G$. vaginalis strains possess a common antigenic determinant although their immunodiffusion technique gave no indication of its molecular mass.

The species-specific antigen defined by Western blotting was not a predominant band in Coomassie blue stained polyacrylamide gels. Since molecules other than proteins, such as lipopolysaccharides, are separated by SDS-PAGE, the question of the nature of the specific antigen arose. Some insight into its structure was obtained by protein digestion of the $G$. vaginalis extract prior to electrophoresis. Since bands did not develop in the lanes of the autoradiogram which contained digested material, it can be concluded that the antigen is partly, if not wholly, proteinaceous. Of course, our observations do not enable us to determine which of the antigens are exposed on the surface, since whole cells were homogenized. Furthermore the number of protein bands observed may be an underestimate of the antigenic complexity of the micro-organism because SDS usually denatures proteins, hence altering their antigenicity. Nevertheless, there is no doubt that a major antigen is common to all $G$. vaginalis strains. This opens the way for raising specific monoclonal antibodies which should not only aid in the diagnosis of $G$. vaginalis infections but also provide a tool for investigating whether the common antigen has a function in terms of attachment and hence pathogenicity.

Y.L.B. is in receipt of an MRC Scholarship for Training in Research Methods.

\section{REFERENCES}

Dunkelberg, W. E., Skaggs, R. \& Kellogg, D. S. (1970). Method for isolation and identification of Corynebacterium vaginale (Haemophilus vaginalis). Applied Microbiology 19, 47-52.

GARDNER, H. L. \& DuKes, C. D. (1955). Haemophilus vaginalis vaginitis. A newly defined specific infection previously classified 'non-specific' vaginitis. American Journal of Obstetrics and Gynecology 69, 962-976.

Greenwood, J. R. \& Picketr, M. J. (1980). Transfer of Haemophilus vaginalis (Gardner and Dukes) to a new genus, Gardnerella: G. vaginalis (Gardner and Dukes) comb. nov. International Journal of Systematic Bacteriology 30, 170-178.

Greenwood, F. C., Hunter, W. M. \& Glover, J. S. (1963). The preparation of ${ }^{131}$ I-labelled human growth hormone of high specific radioactivity. Biochemical Journal 89, 114-123.

LAEMMLI, U. K. (1970). Cleavage of structural protein during the asembly of the head of bacteriophage T4. Nature, London 227, 680-685.

ReYN, A., Birch-Anderson, A. \& Lapage, S. P. (1966). An electron microscopic study of thin sections of Haemophilus vaginalis (Gardner and Dukes) and some possibly related species. Canadian Journal of Microbiology 12, 1125-1136.

SMARON, M. F. \& VICE, J. L. (1974). Analysis of Corynebacterium vaginale by an immunodiffusion technique. Applied Microbiology 27, 469-474.

TAYLOR, E. \& PhILliPS, I. (1983). The identification of Gardnerella vaginalis. Journal of Medical Microbiology 16, 83-92.

TAYLOR-RoBINSON, D. (1984). The bacteriology of Gardnerella vaginalis. In Bacterial Vaginosis, pp. 4155. Edited by P.-A. Mårdh \& D. Taylor-Robinson. Stockholm: Almquist \& Wiksell.

Towbin, H., Strehelin, T. \& Gordon, J. (1979). Electrophoretic transfer of proteins from polyacrylamide gels to nitrocellulose sheets: procedure and some applications. Proceedings of the National Academy of Sciences of the United States of America 79, 4350-4354.

Wang, S. P., Holmes, K. K., KNAPP, J. S., OTt, S. \& KYZER, D. (1977). Immunologic classification of Neisseria gonorrhoeae with micro-immunofluorescence. Journal of Immunology 119, 795-803. 